\title{
Prevalence and Impact on Job Performance of Primary Headache Among Medical and Paramedical Staff in the Emergency Department
}

\author{
Abdulrahman Alzahrani ${ }^{\mathrm{a}, \mathrm{c}}$, Lojain Al-Shehri ${ }^{\mathrm{a}}$, Abdulrahman Alshamrani ${ }^{\mathrm{a}}$, \\ Raed Alharthi ${ }^{a}$, Naif Alomairi ${ }^{b}$
}

\begin{abstract}
Background: The headache is one of the most common neurological disorders and ranks the third cause of years lost due to disability. So this study was conducted to identify the prevalence of headache and its impact on job performance in emergency department medical and paramedical staff.
\end{abstract}

Methods: This was a cross-sectional study using self-administered questionnaire. A total of 308 medical and paramedical staff were selected randomly from emergency departments of Taif hospitals during the period from December 2016 to January 2017.

Results: Three hundred eight staff participated in the study. One hundred fifty-eight $(158,51.3 \%)$ were males and 150 (48.7\%) were females. One hundred thirty-two $(132,42.9 \%)$ were medical staff and $176(57.1 \%)$ were paramedical staff. The last 3 months prevalence of headache among participants was $272(88.3 \%)$ with statistical significant differences with physical activities $(\mathrm{P}=0.008)$ and smoking ( $\mathrm{P}$ $=0.020)$. Regarding the impact of headache, $86(31.6 \%)$ had little to no impact and others had severe impact $(74,27.2 \%)$, remarkable impact $(40,14.7 \%)$ and some impact $(72,26.5 \%)$. There were statistical significant differences $(\mathrm{P} \leq 0.05)$ between headache impact test and age, marital status, specialty, BMI, physical activities, smoking, headache duration, specialist consultation, medication use and frequency of absenteeism.

Conclusion: The primary headache prevalence is very high among medical and paramedical staff in emergency departments. Its characteristics are almost meeting the diagnostic criteria of the tensiontype headache. The impact of headache on job performance is little in most of the staff, but there is significant percent of those with severe impact.

Keywords: Prevalence; Impact; Headache; Medical; Staff; Employ-

\footnotetext{
Manuscript accepted for publication February 07, 2017

${ }^{a}$ College of Medicine, Taif University, Saudi Arabia

bepartment of Internal Medicine, College of Medicine, Taif University, Saudi Arabia

${ }^{\mathrm{c} C}$ Corresponding Author: Abdulrahman Ahmad Alzahrani, College of Medicine, Taif University, Saudi Arabia. Email: aakz1415@gmail.com
}

doi: https://doi.org/10.14740/jnr420e ee; Emergency; Saudi Arabia

\section{Introduction}

The headache is one of the most common neurological disorders. It is in the form of pain and disability that occur in primary headache disorders called cluster, migraine, tension-type headache. The headache can occur due to secondary causes such as medication-overuse headache [1]. So the headache is classified regarding the causes to primary headache that is daily, benign and not caused by underlying disorders and secondary headache is caused by underlying problems such as head injuries and space occupying lesions (e.g. bleeding, tumors, etc.) [2]

According to Global Burden of Disease Study 2013, headache ranked the third cause of years lost due to disability (YLD) [3].

The most common type of headaches is primary headache (more than 90\%), and mostly episodic tension-type headache. Roughly everyone is suffering from this type of headache at least once in his life. In Saudi Arabia, the headache prevalence is $63 \%$ affecting mainly females and younger age. The tensiontype headache has the highest type prevalence $(32 \%)$ and is considered as the common cause of the physician visits and work absenteeism. It is followed by the migraine headache $(2.6-5 \%)[4,5]$.

The medical and paramedical staff are exposed to high work stress that can let them suffer from psychosomatic symptoms such as primary headache. The headache disabilities have an actual effect on job performance, costs and outcomes. Some studies found that $31 \%$ of migraine headache sufferers were losing one workday in a period of 3 months, and absent an ordinary of 10.7 days/year for the sake of headache symptoms. The absenteeism due to migraine headache costs annually $\$ 13$ billion dollars and $\$ 1,165$ dollars for each individual in the USA [6-8].

There is still a lack of sufficient studies to investigate the primary headache prevalence and its impact on the job performance of medical and paramedical staff in the emergency departments. The goals of conducting this study were to determine the prevalence and impact on the job performance of primary headache among medical and paramedical staff in the emergency departments of Taif city hospitals, Saudi Arabia. 


\section{Methods}

A cross-sectional study was designed to assess the prevalence of headache in the emergency department health-related staff and its effect on job performance, using self-administered questionnaire. It includes three parts. The first part collects the socio-demographic data (age, gender, marital status, specialty, body mass index (BMI), physical activity, smoking, income and family history) and determines the participants suffering from headache in the last 3 months. All those participants answered this question with "yes", and they asked to continue the rest of the questionnaire. The second part includes questions about the characteristics of headache. The third part assesses the impact of headache on job performance by using headache impact test (HIT-6) [9]. The score of HIT-6 shows the burden of headache on normal daily life and job performance as the following. 1) Score 60 or more: the headache has very severe impact on the life and job. 2) Score 56 - 59: the headache has a remarkable impact on life and job. 3) Score 50 - 55: the headache has some impact on life and job. 4) Score 49 or less: the headache has little to no impact on life and job.

A total of 308 medical and paramedical staff were selected randomly from emergency departments of Taif hospitals (King Abdul Aziz Specialist Hospital, King Faisal Hospital, Prince Mansour Military Hospital, Al-Hada Military Hospital and AlAmeen Hospital), during the period from December 2016 to January 2017.

All medical and paramedical staff working in emergency department, over 18 years old and either male or female were included in the study. The health care providers suffering from headache due to secondary causes were excluded. All participants were informed about the nature of the study and oral consent was obtained from those who agreed to participate in the study. All participants were informed that their participation in the study is voluntary. The data were coded and entered using Microsoft Excel 2010, and then analyzed using SPSS program version 0.21 .

\section{Results}

\section{Socio-demographic data}

Three hundred eight medical and paramedical emergency department staff participated in the study. Most of the participants were males $(51.3 \%)$, aged $25-39$ years $(57.1 \%)$, single (51.9\%), paramedical (57.1\%), with body mass index (BMI) of $24 \pm 5$ (mean \pm standard deviation (SD)), not performing $\geq$ 30 min of physical activities (48.1\%), non-smoker and 5,000 - 10,000 SR income/month (79.9\% and 55.8\%, respectively) (Table 1).

\section{Prevalence of headache}

The last 3 months prevalence of headache among participants was $88.3 \%$. It was common in the age group ranging from 40
Table 1. Socio-Demographic Data of the Study Sample $(N=308)$

\begin{tabular}{|c|c|c|}
\hline & $\mathbf{N}$ & $\%$ \\
\hline \multicolumn{3}{|l|}{ Age } \\
\hline $18-24$ & 80 & $26 \%$ \\
\hline $25-39$ & 176 & $57.1 \%$ \\
\hline $40-59$ & 52 & $16.9 \%$ \\
\hline Total & 308 & $100 \%$ \\
\hline \multicolumn{3}{|l|}{ Gender } \\
\hline Male & 158 & $51.3 \%$ \\
\hline Female & 150 & $48.7 \%$ \\
\hline Total & 308 & $100 \%$ \\
\hline \multicolumn{3}{|l|}{ Marital status } \\
\hline Single & 160 & $51.9 \%$ \\
\hline Married & 144 & $46.8 \%$ \\
\hline Divorced/widow & 4 & $1.3 \%$ \\
\hline Total & 308 & $100 \%$ \\
\hline \multicolumn{3}{|l|}{ Specialty } \\
\hline Medical & 132 & $42.9 \%$ \\
\hline Paramedical & 176 & $57.1 \%$ \\
\hline Total & 308 & $100 \%$ \\
\hline \multicolumn{3}{|l|}{ Body mass index (BMI) } \\
\hline Underweight & 36 & $11.7 \%$ \\
\hline Normal & 148 & $48.1 \%$ \\
\hline Overweight & 80 & $26.0 \%$ \\
\hline Obese & 44 & $14.3 \%$ \\
\hline Total & 308 & $100.0 \%$ \\
\hline $\mathrm{BMI}$, mean $\pm \mathrm{SD}$ & $24 \pm 5$ & \\
\hline \multicolumn{3}{|c|}{ Physical activities $\geq 30 \mathrm{~min} /$ week } \\
\hline Never & 148 & $48.1 \%$ \\
\hline 1 & 56 & $17.5 \%$ \\
\hline $1-3$ & 70 & $22.7 \%$ \\
\hline+3 & 36 & $11.7 \%$ \\
\hline Total & 308 & $100.0 \%$ \\
\hline \multicolumn{3}{|l|}{ Smoking } \\
\hline Yes & 62 & $20.1 \%$ \\
\hline No & 246 & $79.9 \%$ \\
\hline Total & 308 & $100.0 \%$ \\
\hline \multicolumn{3}{|l|}{ Income } \\
\hline $5,000-10,000 \mathrm{SR}$ & 172 & $55.8 \%$ \\
\hline $10,000-15,000 \mathrm{SR}$ & 88 & $28.6 \%$ \\
\hline$+15,000 \mathrm{SR}$ & 48 & $15.6 \%$ \\
\hline Total & 308 & $100.0 \%$ \\
\hline \multicolumn{3}{|l|}{ Family history } \\
\hline Yes & 122 & $39.6 \%$ \\
\hline No & 186 & $60.4 \%$ \\
\hline Total & 308 & $100.0 \%$ \\
\hline \multicolumn{3}{|l|}{ Headache last 3 months } \\
\hline Yes & 272 & $88.3 \%$ \\
\hline No & 36 & $11.7 \%$ \\
\hline Total & 308 & $100.0 \%$ \\
\hline
\end{tabular}


Table 2. Association Between Socio-Demographic Data and Headache Occurrence in the Last 3 Months

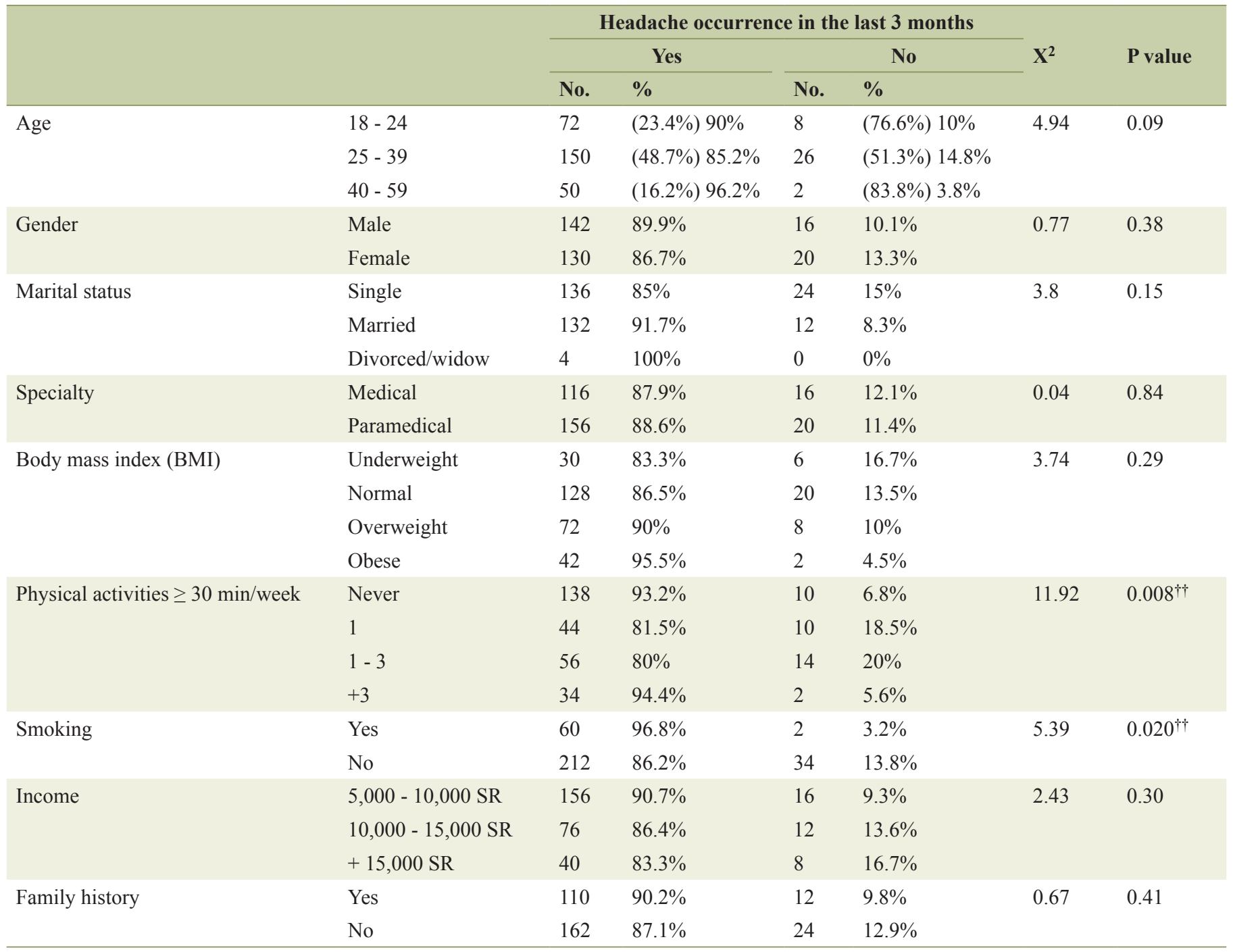

†'Statistically significant difference. ( $\mathrm{n}, \%$ ) Column percent (of all samples).

to 59 years $(96.2 .1 \%)$, male $(89.2 \%)$, divorced $(100 \%)$, paramedical $(88.1 \%)$, obese $(95.5 \%)$, those performing physical activities $\geq 30 \mathrm{~min}$ more than three times per week $(94.4 \%)$, smokers (96.8\%), those with monthly income between 5000 and 10,000 SR $(90.7 \%)$ and those with positive family history of headache $(90.2 \%)$.

There were statistical significant differences between headache occurrence in the last 3 months and physical activities $\geq$ $30 \mathrm{~min} /$ week $(\mathrm{P}=0.008)$ and smoking $(\mathrm{P}=0.020)$ (Table 2$)$.

\section{Headache characteristics}

The characteristics of headache are presented in Table 3. Of the participants, 58.8\% suffered from headache for less than 3 years. The headache happened often weekly in $51.5 \%$ of participants. It was almost bilateral (56.6\%), dull/pressing (52.9\%) in character, gradually $(42.6 \%)$ in onset, moderate in intensity
(58.1\%), not increasing in frequency $(58.8 \%)$, occurring in the evening $(53.7 \%)$, relieving in hours with medications $(50 \%)$ and without medications (64\%), worsening by physical activities $(57.4 \%)$ and not associated with nausea (66.9\%), vomiting $(85.3 \%)$, sensitivity to light $(52.9 \%)$ and neurological deficiencies $(83.8 \%)$, but associated with sensitivity to noise $(53.7 \%)$.

Of the participants $73.5 \%$ did not seek a consultation with specialist and were not absent from work due to headache; $49.3 \%$ did not use medications for their headache complaint.

\section{HIT-6}

More than one-fourth of participants have little to no impact $(31.6 \%)$ and others have severe impact $(27.2 \%)$, remarkable impact (14.7\%) and some impact (26.5\%) (Fig. 1).

There were statistical significant differences $(\mathrm{P} \leq 0.05)$ between HIT-6 and age, marital status, specialty, BMI, physical 
Table 3. Headache Characteristics $(N=272)$

\begin{tabular}{|c|c|c|}
\hline & $\mathbf{N}$ & $\%$ \\
\hline \multicolumn{3}{|l|}{ Headache duration (years) } \\
\hline $1-3$ years & 160 & $58.8 \%$ \\
\hline $3-5$ years & 44 & $16.2 \%$ \\
\hline+5 years & 68 & $25 \%$ \\
\hline \multicolumn{3}{|l|}{ Headache frequency } \\
\hline Daily & 34 & $12.5 \%$ \\
\hline Weekly & 140 & $51.5 \%$ \\
\hline Monthly & 98 & $36 \%$ \\
\hline \multicolumn{3}{|l|}{ Headache site } \\
\hline Bilateral & 154 & $56.6 \%$ \\
\hline One-sided & 118 & $43.4 \%$ \\
\hline \multicolumn{3}{|l|}{ Headache character } \\
\hline Pulsating/throbbing & 128 & $47.1 \%$ \\
\hline Dull/pressing & 144 & $52.9 \%$ \\
\hline \multicolumn{3}{|l|}{ Headache onset } \\
\hline Gradually & 116 & $42.6 \%$ \\
\hline Suddenly & 78 & $28.7 \%$ \\
\hline Varies & 78 & $28.7 \%$ \\
\hline \multicolumn{3}{|l|}{ Headache intensity } \\
\hline Mild & 74 & $27.2 \%$ \\
\hline Moderate & 158 & $58.1 \%$ \\
\hline Severe & 40 & $14.7 \%$ \\
\hline \multicolumn{3}{|c|}{ Headaches increasing in frequency } \\
\hline Yes & 112 & $41.2 \%$ \\
\hline No & 160 & $58.8 \%$ \\
\hline \multicolumn{3}{|l|}{ Headache time } \\
\hline Morning & 68 & $25 \%$ \\
\hline Evening & 146 & $53.7 \%$ \\
\hline Night & 58 & $21.3 \%$ \\
\hline \multicolumn{3}{|c|}{ Headache relieving (with medications) } \\
\hline Minutes & 44 & $16.2 \%$ \\
\hline Hours & 136 & $50 \%$ \\
\hline Days & 18 & $6.6 \%$ \\
\hline No medication use & 74 & $27.2 \%$ \\
\hline \multicolumn{3}{|c|}{ Headache relieving (without medications) } \\
\hline Minutes & 46 & $16.9 \%$ \\
\hline Hours & 174 & $64 \%$ \\
\hline Days & 52 & $19.1 \%$ \\
\hline \multicolumn{3}{|c|}{ Headache worsened by physical activities } \\
\hline Yes & 156 & $57.4 \%$ \\
\hline No & 116 & $42.6 \%$ \\
\hline \multicolumn{3}{|c|}{ Headaches associated with nausea } \\
\hline Yes & 90 & $33.1 \%$ \\
\hline
\end{tabular}


Table 3. Headache Characteristics $(\mathrm{N}=272)$ (continued)

\begin{tabular}{|c|c|c|}
\hline & $\mathbf{N}$ & $\%$ \\
\hline No & 182 & $66.9 \%$ \\
\hline \multicolumn{3}{|c|}{ Headaches associated with vomiting } \\
\hline Yes & 40 & $14.7 \%$ \\
\hline No & 232 & $85.3 \%$ \\
\hline \multicolumn{3}{|l|}{ Sensitivity to light } \\
\hline Yes & 128 & $47.1 \%$ \\
\hline No & 144 & $52.9 \%$ \\
\hline \multicolumn{3}{|l|}{ Sensitivity to noise } \\
\hline Yes & 146 & $53.7 \%$ \\
\hline No & 126 & $46.3 \%$ \\
\hline \multicolumn{3}{|l|}{ Neurological deficiencies } \\
\hline Yes & 44 & $16.2 \%$ \\
\hline No & 228 & $83.8 \%$ \\
\hline \multicolumn{3}{|l|}{ Specialist consultation } \\
\hline General practitioner & 24 & $8.8 \%$ \\
\hline Family Physician & 18 & $6.6 \%$ \\
\hline Neurologist & 30 & $11 \%$ \\
\hline None & 200 & $73.5 \%$ \\
\hline \multicolumn{3}{|l|}{ Medication use } \\
\hline No medication & 134 & $49.3 \%$ \\
\hline Prescription & 46 & $16.9 \%$ \\
\hline Over the counter & 92 & $33.8 \%$ \\
\hline \multicolumn{3}{|l|}{ Frequency of absenteeism } \\
\hline 1 - 5 days & 46 & $16.9 \%$ \\
\hline 5 - 10 days & 20 & $7.4 \%$ \\
\hline+10 days & 6 & $2.2 \%$ \\
\hline None & 200 & $73.5 \%$ \\
\hline
\end{tabular}

activities, smoking, headache duration, specialist consultation, medication use and frequency of absenteeism. There were not HIT-6 and gender and income.

The severe impact of headache was almost affecting those people aged from 40 to 59 (48\%), married (33.3\%), medical $(39.7 \%)$, obese $(100 \%)$, having headache more than 3 years $(33.6 \%)$, consulting neurologist $(60 \%)$, on over the counter medications $(32.6 \%)$ and absent 5 - 10 days per year $(60 \%)$ (Table 4).

\section{Discussion}

The headache is the most common neurological disorder that causes disabilities and has an impact on job performance among population $[6,8]$. Multiple studies have reported the prevalence of headache in the health workers. But the studies denoting the headache and its impact among emergency department staff are rare. To date, this study is the first one that

Headache Impact Test (HIT-6)

Little to no impact $\quad$ Some impact

a Remarkable impact $\mathbf{a}$ Severe impact

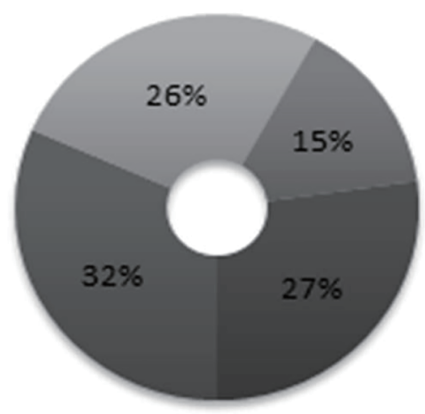

Figure 1. Headache Impact Test (HIT-6). 
Table 4. Headache Impact Test $(\mathrm{HIT}-6)(\mathrm{N}=272)$

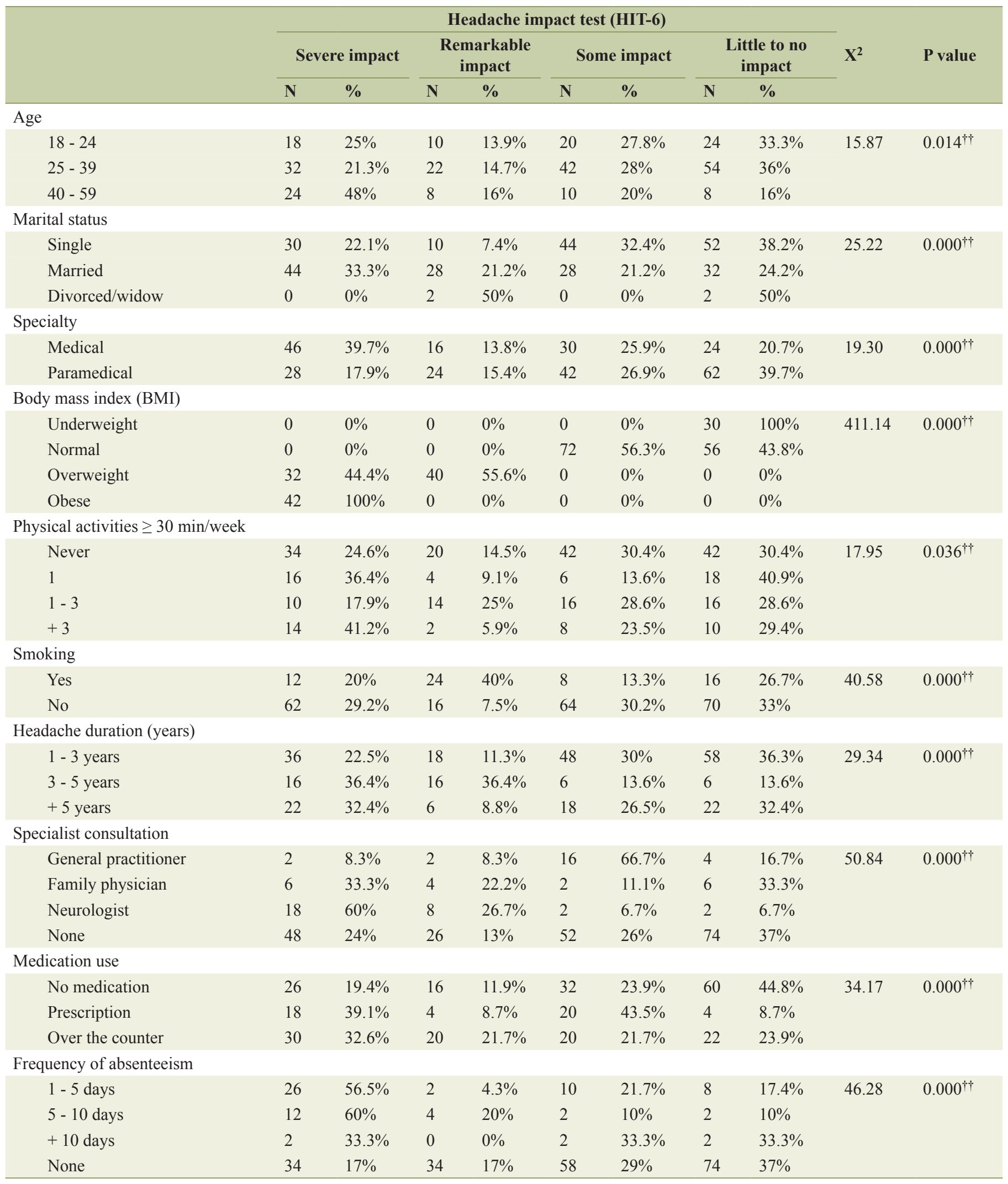

t†Statistically significant difference. 
assesses the prevalence of headache and its impact on job performance among medical and paramedical staff in the emergency departments in the hospitals of Saudi Arabia.

The health care works need a concentration, hard work and effort. Absence or weariness of one of the emergency department staff for 1 day or some time can affect the health care process [10]. So the headache needs evaluating and managing among medical and paramedical staff as all and specifically those working in the emergency departments.

In our study, we found the last three months prevalence of headache among medical and paramedical emergency department staff is $88.3 \%$ (Table 1 ), $87.9 \%$ of medical and $88.6 \%$ of paramedical (Table 2). This prevalence is much higher than the mean of global headache prevalence $46 \%$ as well as the general population prevalence in Saudi Arabia 63\% [5, 11]. And the other studies among varies Health Care Workers (HCWs) that conducted in Switzerland, Nigeria, Taiwan and North China offer $61 \%, 39.3 \%, 49.6 \%$ and $45.3 \%$, respectively [1215]. These stringent results refer to the burden of stress that affecting health care professionals and exactly the emergency department staff [16]

The statistical significant difference is shown in Table 2 between headache prevalence in the last 3 months and doing physical activities $\geq 30$ min more than thrice a week $(\mathrm{P}=$ $0.008)$, because the headache is triggered by physical activities in $57.4 \%$ of the participants and this is supported by Zivadinov and colleagues study that suggested the physical activity is one of the most triggers of headache [17]. As well as the smoking has an association with headache prevalence $(\mathrm{P}=0.020)$, smokers have a higher prevalence of headache $(96.8 \%)$ than non-smokers $(86.2 \%)$. This implies that smoking has a negative effect on the headache occurrence as in Qi Gan and colleagues study (2016) [18]. But this issue is conflicting according to Taylor (2015) [19].

The headache characteristics among the study sample were weekly in $51.5 \%$ (Table 3 ). It is almost bilateral $(56.6 \%)$, dull/pressing $(52.9 \%)$ in character, gradually $(42.6 \%)$ in onset, moderate in intensity $(58.1 \%)$, not increasing in frequency (58.8\%), occurring in the evening $(53.7 \%)$, relieving in hours with medications (50\%) and without medications (64\%), worsening by physical activities $(57.4 \%)$ and not associated with nausea $(66.9 \%)$, vomiting $(85.3 \%)$, sensitivity to light $(52.9 \%)$ and neurological deficiencies $(83.8 \%)$, but associated with sensitivity to noise $(53.7 \%)$. Most of these characteristics are meeting the diagnostic criteria of the tension-type headache of the headache disorders classification, third edition beta version (ICHD-3 beta) by International Headache Society, except the triggering of headache by physical activities and the sensitivity to noise (phonophobia) [20]. Regarding the worsening of headache by the physical activities, it is one of the migraine criteria, according to the International Headache Society (ICHD-3 beta). As for phonophobia, if it occurs not more than once, it may be considered as tension-type headache. Overall, these characteristics may suggest that the tension-type headache is the type of primary headache most affecting the medical and paramedical staff in emergency department, and it is propped by Sokolovic et al (2013) [12].

Unfortunately, the headache has a severe impact on the life and job performance of $27.2 \%$ of the emergency department staff (Fig. 1). Also, 36.4\% of them were absent from work due to the headache for 5 - 10 days in the past year (2016). Hence, this causes work productivity decline and defect in the health care providing process [10]. These results can illustrate the high percent $(60 \%)$ of seeking a consultation from a neurologist rather than other specialists and using prescribed medications $(39.1 \%)$ (Table 4). But when we discerned these sufferer staff, we found they almost have risk factors of developing headache, such as obesity and over the counter medications use [21]. So the risk factors, mainly modifiable, have to be taken into account beside the life and work stress impact. The age group most severely affected by primary headache was between 40 and 59 years, and that affected little to no impact was 25 - 39 years. This is antithesis of many studies which assume the primary headache is decreasing during the aging $[22,23]$. Fortunately still $31.6 \%$ of participants have a little and even no impact by headache on their life and jobs, and they represent most of the medical and paramedical emergency department staff in Saudi Arabia.

Finally, we recommend conducting further studies to assessing the prevalence of headache and its impact on life and job performance in the health care field employee as all. Also, the documentation of the headache suffering employee is important, to take into account their conditions and so help them to overcome it and improve their life quality. Subsequently, this will increase the work productivity and decrease the burden of headache.

\section{Conclusion}

The primary headache prevalence is very high among medical and paramedical staff in emergency departments. Its characteristics are almost meeting the diagnostic criteria of the tensiontype headache. The impact of headache on job performance is little in most of the staff, but there is significant percent of those with severe impact.

\section{Acknowledgments}

We thank Rayan Nasser Alharthi, Mazen Abdullah Alzaedi, Badr Edrees Alnamie, Rahaf Ghazi Altwairqi, Nourah Ali Alshamrani, Abrar Fahad Alotaibi; in their active role in Data collection phase.

\section{References}

1. WHO. Headache disorders Fact sheet Updated April. 2016.

2. Goadsby PJ, Raskin NH. Chapter 14. Headache. In: Longo DL, Fauci AS, Kasper DL, Hauser SL, Jameson J, Loscalzo J. eds. Harrison's Principles of Internal Medicine, 18e. New York, NY: McGraw-Hill; 2012.

3. Global, regional, and national incidence, prevalence, and years lived with disability for 301 acute and chronic diseases and injuries in 188 countries, 1990-2013: a sys- 
tematic analysis for the Global Burden of Disease Study 2013. Lancet. 2015;386(9995):743-800.

4. Kunkel, Robert S. "Headache". Disease Management Project: Publications. Cleveland Clinic. Retrieved 201008-06.

5. Al Jumah M, Al Khathaami A, Kojan S, Hussein M, Stovner L, Steiner T, Al saleh L. The Burden of Primary Headache Disorders in Saudi Arabia. Neurology Journals. Retrieved from http://www.neurology.org/content/80/7 Supplement/P03.112.short.

6. Lin KC, et al. Association between stress at work and primary headache among nursing staff in Taiwan. Headache. 2007.

7. Kessler RC, Shahly V, Stang PE, Lane MC. The associations of migraines and other headaches with work performance: results from the National Comorbidity Survey Replication (NCS-R). Cephalalgia. 2010;30(6):722-734.

8. Lipton RB, Stewart WF, Diamond S, Diamond ML, Reed M. Prevalence and burden of migraine in the United States: data from the American Migraine Study II. Headache. 2001;41(7):646-657.

9. Yang M, Rendas-Baum R, Varon SF, Kosinski M. Validation of the Headache Impact Test (HIT-6) across episodic and chronic migraine. Cephalalgia. 2011;31(3):357-367.

10. Aluko OO, Adebayo AE, Adebisi TF, Ewegbemi MK, Abidoye AT, Popoola BF. Knowledge, attitudes and perceptions of occupational hazards and safety practices in Nigerian healthcare workers. BMC Res Notes. 2016;9:71.

11. Stovner L, Hagen K, Jensen R, Katsarava Z, Lipton R, Scher A, Steiner T, et al. The global burden of headache: a documentation of headache prevalence and disability worldwide. Cephalalgia. 2007;27(3):193-210.

12. Sokolovic E, Riederer F, Szucs T, Agosti R, Sandor PS Self-reported headache among the employees of a Swiss university hospital: prevalence, disability, current treat- ment, and economic impact. J Headache Pain. 2013;14:29.

13. Oshinaike O, Ojo O, Okubadejo N, Ojelabi O, Dada A. Primary headache disorders at a tertiary health facility in Lagos, Nigeria: prevalence and consultation patterns. Biomed Res Int. 2014;2014:782915.

14. Lin KC, Huang CC, Wu CC. Association between stress at work and primary headache among nursing staff in Taiwan. Headache. 2007;47(4):576-584.

15. Wang Y, Xie J, Yang F, Wu S, Wang H, Zhang X, Liu $\mathrm{H}$, et al. The prevalence of primary headache disorders and their associated factors among nursing staff in North China. J Headache Pain. 2015;16:4.

16. Patrick PK. Burnout: job hazard for health workers. Hospitals. 1979;53(22):87-88, 90.

17. Zivadinov R, Willheim K, Sepic-Grahovac D, Jurjevic A, Bucuk M, Brnabic-Razmilic O, Relja G, et al. Migraine and tension-type headache in Croatia: a population-based survey of precipitating factors. Cephalalgia. 2003;23(5):336-343.

18. Gan WQ, Estus S, Smith JH. Association Between Overall and Mentholated Cigarette Smoking With Headache in a Nationally Representative Sample. Headache. 2016;56(3):511-518.

19. Taylor FR. Tobacco, Nicotine, and Headache. Headache. 2015;55(7):1028-1044.

20. The International Classification of Headache Disorders, 3rd edition (beta version). Cephalalgia. 2013;33(9):629808.

21. Garza I, et al. Overview of chronic daily headache. http:// www.uptodate.com/home. Accessed Jan. 6, 2015.

22. Armstrong Carol L, Lisa Morrow. Handbook of Medical Neuropsychology: Applications of Cognitive Neuroscience. New York: Springer, 2010.

23. Bravo TP. Headaches of the elderly. Curr Neurol Neurosci Rep. 2015;15(6):30. 